\title{
Comparison of Antibacterial Activity of Calcium Hydroxide, Azadirachta Indica (Neem), Ocimum Tenuiflorum (Tulsi) and Punica Granatum (Pomegranate) Gels as Intracanal Medicaments Against Enterococcus Faecalis: An In-vitro Study
}

\author{
Akanksha Mittal, Sunil Tejaswi*, Mruthunjaya K, Suneeth Shetty, Ambikathanaya UK
}

Akanksha Mittal, Sunil Tejaswi*, Mruthunjaya K, Suneeth Shetty, Ambikathanaya UK

JSS Dental College and Hospital, Mysuru, INDIA.

\section{Correspondence \\ Sunil Tejaswi}

JSS Dental College and Hospital, Mysuru, INDIA.

E-mail: sunilkasipalli@gmail.com

History

- Submission Date: 28-03-2021;

- Review completed: 21-04-2021;

- Accepted Date: 25-05-2021.

DOI : 10.5530/pj.2021.13.127

Article Available online

http://www.phcogj.com/v13/i4

Copyright

(C) 2021 Phcogj.Com. This is an openaccess article distributed under the terms of the Creative Commons Attribution 4.0 International license.

\begin{abstract} then randomly distributed into 4 groups.

Group I- Calcium hydroxide

Group II- 5\% A. indica (Neem) gel

Group III- 10\% O. tenuiflorum (Tulsi) gel

Group IV-10\% P. granatum (Pomegranate) gel canal therapy, Microbial sensitivity tests.

\section{INTRODUCTION}

It is well established that bacteria play a crucial role in the development of apical periodontitis. ${ }^{1}$ Invariably, elimination of all bacteria from the root canal is one of the main objectives of endodontic treatment as their persistence results in endodontic infection. ${ }^{2}$ This goal is achieved by the process of mechanical instrumentation along with the usage of various irrigants and intracanal medicaments between appointments.
\end{abstract}

Aim: This study aimed to evaluate the antibacterial activity of Calcium hydroxide, Azadirachta indica (Neem), Ocimum tenuiflorum (Tulsi) and Punica granatum (Pomegranate) gels as intracanal medicaments against Enterococcus faecalis. Methodology: Crude extracts of Pomegranate peel, Neem leaves and Tulsi leaves were used to determine MIC following which gels of $5 \%$ neem, $10 \%$ tulsi and $10 \%$ pomegranate were prepared. Forty-eight single rooted human premolars were procured and inoculated with E.faecalis for 7 days. Specimens were

The experimental gels were then introduced into the samples and were sealed at both ends. The antimicrobial activity of medicaments was assessed by measuring CFU/ml at the end of 1,3 and 5 days. Results: Calcium hydroxide showed the maximum antibacterial activity $\left(5.3 \times 10^{4} \mathrm{CFU} / \mathrm{ml}\right)$ followed by Pomegranate gel $\left(5.4 \times 10^{4} \mathrm{CFU} / \mathrm{ml}\right)$ with no statistically significant difference between them. Similarly, no statistically significant difference was observed between the mean CFU/ml values of the neem $\left(10.2 \times 10^{4} \mathrm{CFU} / \mathrm{ml}\right)$ and tulsi gel $(10.2$ $\mathrm{X} 10^{4} \mathrm{CFU} / \mathrm{ml}$ ). However, pomegranate gel showed statistically significant antibacterial activity when compared to Neem and Tulsi. (Table 1, Table 2, Table 3, table 4) (Figure 1). Conclusion: Calcium hydroxide showed the best antibacterial activity against E. faecalis. Among herbal gels, pomegranate showed the maximum antibacterial activity, however, further in-vivo research is required for it to be used as a sole intracanal medicament clinically.

Key words: Intracanal medicaments, Calcium hydroxide, Herbal, Enterococcus faecalis, Root

E. faecalis is a gram-positive cocci and facultative anaerobe which can survive extreme $\mathrm{pH}(9.6)$, salt concentration and a temperature of $60^{\circ} \mathrm{C}$ for 30 min. ${ }^{3-4}$ It has a key role in the formation of periradicular lesions post endodontic treatment. This persistent pathogen can survive within the root canal system as an isolated organism making up the major part of the flora and is known to be found in $22-77 \%$ of endodontic failure cases. ${ }^{3}$ Because of its ability to form biofilm, E. Faecalis becomes more impervious to phagocytic activity, antibodies and antibacterial agents making it survivable in harshest conditions. ${ }^{5}$ Both forms of periradicular diseases, primary (4-44\%) and persistent endodontic infections (24-74\%) have been known to be associated with E. faecalis. The resistance of the E. faecalis increases from 1000-fold to 10,000-fold when it is devoid of nutrition. ${ }^{6}$

Since the 1920 s, calcium hydroxide $\left[\mathrm{Ca}(\mathrm{OH})_{2}\right]$ is the most frequently placed endodontic medicament. Calcium hydroxide has many favorable properties such as high $\mathrm{pH}$ (12.5-12.8 approximately), insolubility in alcohol \& low solubility in water. Its low water solubility is particularly advantageous as it provides us with a longer period before it dissolves in tissue fluids. ${ }^{8}$ However, Calcium hydroxide has been reported inefficient against E.faecalis.

E. faecalis has the ability to colonize inside of dentinal tubules and thus can elude the hydroxyl ions. Also, ramifications, irregularities \& isthmuses contain necrotic tissue that can shield bacteria from effect of calcium hydroxide. ${ }^{9}$

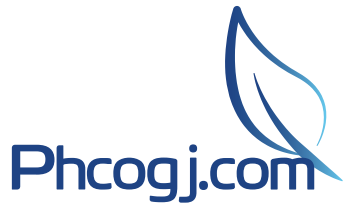

Cite this article: Mittal A, Tejaswi S, Mruthunjaya K, Shetty S, Ambikathanaya UK. Comparison of Antibacterial Activity of Calcium Hydroxide, Azadirachta Indica (Neem), Ocimum Tenuiflorum (Tulsi) and Punica Granatum (Pomegranate) Gels as Intracanal Medicaments Against Enterococcus Faecalis: An In-vitro Study. Pharmacogn J. 2021;13(4): 988-994. 
Mittal A, et al:: Comparison of Antibacterial Activity of Calcium Hydroxide, Azadirachta Indica (Neem), Ocimum Tenuiflorum (Tulsi) and Punica Granatum (Pomegranate) Gels as Intracanal Medicaments Against Enterococcus Faecalis: An In-vitro Study

Table 1: Descriptive statistics and ANOVA of different groups across different time intervals (All mean values are in $10^{4} \mathrm{CFU} / \mathrm{ml}$ ).

\begin{tabular}{|c|c|c|c|c|c|c|c|c|c|c|c|c|}
\hline \multirow{2}{*}{$\begin{array}{l}\text { DAYS } \\
\text { GROUPS }\end{array}$} & \multicolumn{4}{|c|}{ DAY 1} & \multicolumn{4}{|c|}{ DAY 3} & \multicolumn{4}{|c|}{ DAY 5} \\
\hline & $\mathrm{I}$ & II & III & IV & I & II & III & IV & I & II & III & IV \\
\hline $\mathrm{N}$ & 4 & 4 & 4 & 4 & 4 & 4 & 4 & 4 & 4 & 4 & 4 & 4 \\
\hline Mean & 8.60 & 10.60 & 11.10 & 8.73 & 7.20 & 10.30 & 10.87 & 7.60 & 5.30 & 10.27 & 10.20 & 5.47 \\
\hline S.D. & 0.72 & 0.92 & 0.20 & 0.42 & 0.26 & 0.17 & 0.21 & 0.26 & 0.10 & 0.12 & 0.10 & 0.15 \\
\hline S.E. & 0.42 & 0.53 & 0.12 & 0.24 & 0.15 & 0.10 & 0.12 & 0.15 & 0.06 & 0.07 & 0.06 & 0.09 \\
\hline 95\% C.I. & $\begin{array}{l}6.81- \\
10.39\end{array}$ & $\begin{array}{l}8.32- \\
12.88\end{array}$ & $\begin{array}{c}10.06- \\
11.59\end{array}$ & $7.69-9.76$ & $\begin{array}{c}6.54- \\
7.86\end{array}$ & $\begin{array}{l}9.87- \\
10.73\end{array}$ & $\begin{array}{c}10.35- \\
11.38\end{array}$ & $6.94-8.26$ & $\begin{array}{c}5.05- \\
5.55\end{array}$ & $\begin{array}{l}9.98- \\
10.56\end{array}$ & $\begin{array}{l}9.95- \\
10.45\end{array}$ & $\begin{array}{c}5.08- \\
5.85\end{array}$ \\
\hline \multicolumn{13}{|l|}{ ANOVA } \\
\hline df & \multicolumn{4}{|c|}{3} & \multicolumn{3}{|c|}{3} & \multicolumn{5}{|c|}{3} \\
\hline $\mathrm{F}$ & \multicolumn{4}{|c|}{12.46} & \multicolumn{3}{|c|}{194.52} & \multicolumn{5}{|c|}{1661.55} \\
\hline Significance & \multicolumn{3}{|c|}{0.002} & & \multicolumn{3}{|c|}{0.001} & \multicolumn{5}{|c|}{0.001} \\
\hline
\end{tabular}

Table 2: Groupwise comparison of Mean CFU/ml at Day 1.

\begin{tabular}{|c|c|c|c|c|c|c|}
\hline \multirow{2}{*}{ Groups } & \multirow{2}{*}{ Groups } & \multirow{2}{*}{ Mean Difference } & \multirow{2}{*}{ Std. Error } & \multirow{2}{*}{ Sig. } & \multicolumn{2}{|c|}{ 95\% Confidence Interval } \\
\hline & & & & & Lower Bound & Upper Bound \\
\hline \multirow{3}{*}{1} & 2 & -2.00 & 0.51 & 0.02 & -3.64 & -0.36 \\
\hline & 3 & -2.50 & 0.51 & 0.01 & -4.14 & -0.86 \\
\hline & 4 & -0.13 & 0.51 & 0.99 & -1.77 & 1.51 \\
\hline \multirow{3}{*}{2} & 1 & $2.00^{*}$ & 0.51 & 0.02 & 0.36 & 3.64 \\
\hline & 3 & -0.50 & 0.51 & 0.77 & -2.14 & 1.14 \\
\hline & 4 & $1.87^{\star}$ & 0.51 & 0.03 & 0.23 & 3.51 \\
\hline \multirow{3}{*}{3} & 1 & $2.50^{*}$ & 0.51 & 0.01 & 0.86 & 4.14 \\
\hline & 2 & 0.50 & 0.51 & 0.77 & -1.14 & 2.14 \\
\hline & 4 & $2.37^{\star}$ & 0.51 & 0.01 & 0.73 & 4.01 \\
\hline
\end{tabular}

*. The mean difference is significant at the 0.05 level.

Table 3: Groupwise comparison of Mean CFU/ml at Day 3.

\begin{tabular}{|c|c|c|c|c|c|c|}
\hline \multirow{2}{*}{ Groups } & \multirow{2}{*}{ Groups } & \multirow{2}{*}{ Mean Difference } & \multirow{2}{*}{ Std. Error } & \multirow{2}{*}{ Sig. } & \multicolumn{2}{|c|}{ 95\% Confidence Interval } \\
\hline & & & & & Lower Bound & Upper Bound \\
\hline \multirow{3}{*}{1} & 2 & -3.10 & 0.19 & 0.00 & -3.70 & -2.50 \\
\hline & 3 & -3.67 & 0.19 & 0.00 & -4.27 & -3.06 \\
\hline & 4 & -0.40 & 0.19 & 0.23 & -1.00 & 0.20 \\
\hline \multirow{3}{*}{2} & 1 & $3.10^{*}$ & 0.19 & 0.00 & 2.50 & 3.70 \\
\hline & 3 & -0.57 & 0.19 & 0.07 & -1.17 & 0.04 \\
\hline & 4 & $2.70^{\star}$ & 0.19 & 0.00 & 2.10 & 3.30 \\
\hline \multirow{3}{*}{3} & 1 & $3.67^{\star}$ & 0.19 & 0.00 & 3.06 & 4.27 \\
\hline & 2 & 0.57 & 0.19 & 0.07 & -0.04 & 1.17 \\
\hline & 4 & $3.27^{*}$ & 0.19 & 0.00 & 2.66 & 3.87 \\
\hline
\end{tabular}

The mean difference is significant at the 0.05 level.

Table 4: Groupwise comparison of Mean CFU/ml at Day 5.

\begin{tabular}{|c|c|c|c|c|c|c|}
\hline \multirow{2}{*}{ Groups } & \multirow{2}{*}{ Groups } & \multirow{2}{*}{ Mean Difference } & \multirow{2}{*}{ Std. Error } & \multirow{2}{*}{ Sig. } & \multicolumn{2}{|c|}{ 95\% Confidence Interval } \\
\hline & & & & & Lower Bound & Upper Bound \\
\hline \multirow{3}{*}{1} & 2 & -4.97 & 0.10 & 0.00 & -5.28 & -4.66 \\
\hline & 3 & -4.90 & 0.10 & 0.00 & -5.21 & -4.59 \\
\hline & 4 & -0.17 & 0.10 & 0.38 & -0.48 & 0.15 \\
\hline \multirow{3}{*}{2} & 1 & $4.97^{\star}$ & 0.10 & 0.00 & 4.66 & 5.28 \\
\hline & 3 & 0.07 & 0.10 & 0.90 & -0.25 & 0.38 \\
\hline & 4 & $4.80^{*}$ & 0.10 & 0.00 & 4.49 & 5.11 \\
\hline \multirow{3}{*}{3} & 1 & $4.90^{*}$ & 0.10 & 0.00 & 4.59 & 5.21 \\
\hline & 2 & -0.07 & 0.10 & 0.90 & -0.38 & 0.25 \\
\hline & 4 & $4.73^{\star}$ & 0.10 & 0.00 & 4.42 & 5.05 \\
\hline
\end{tabular}

The mean difference is significant at the 0.05 level. 


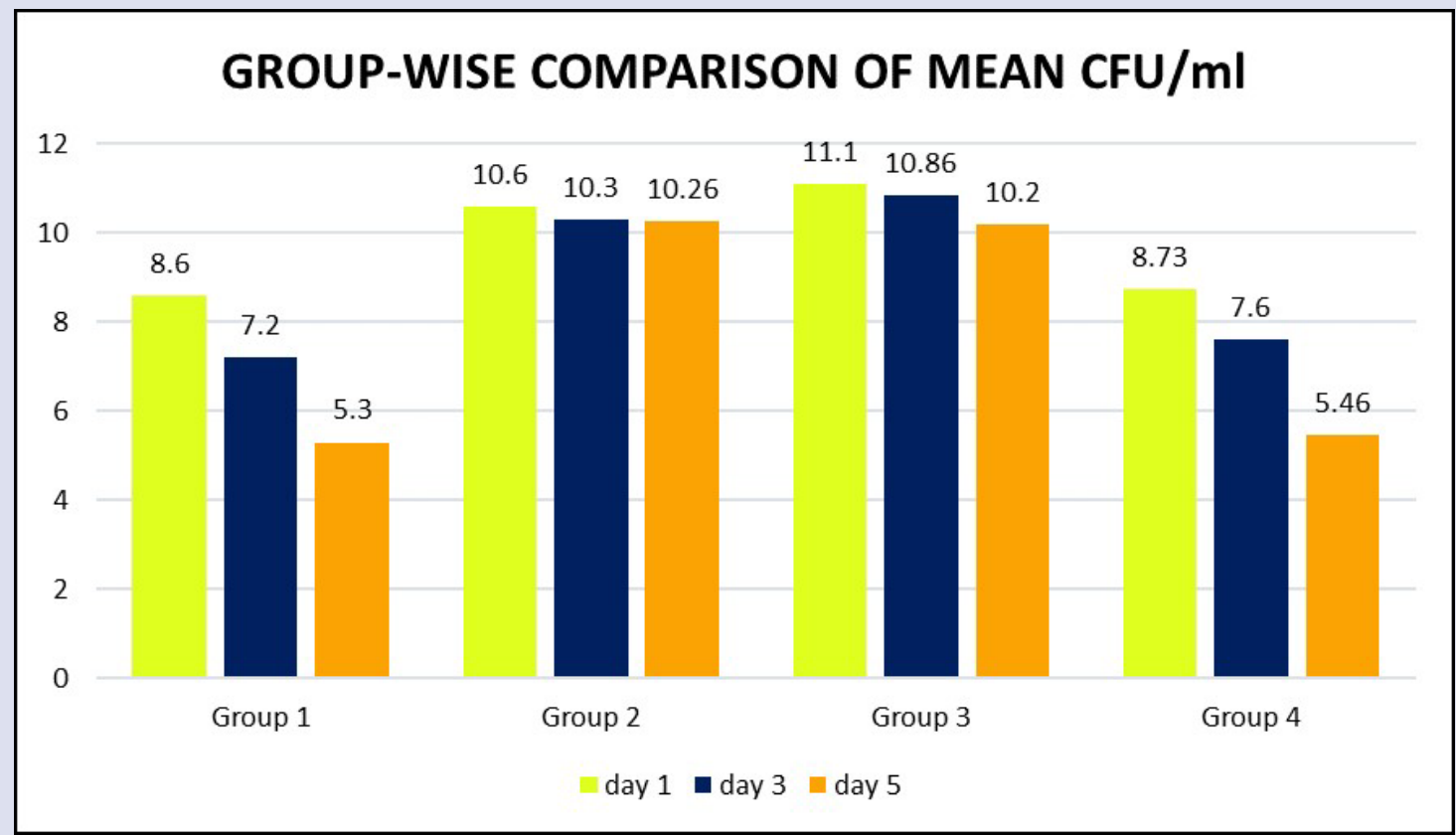

Figure 1: Group-wise comparison of Mean CFU/ml over different time intervals.

Presently, most of the commercial products used in Endodontics as intracanal medicaments are cytotoxic and are unable to eradicate bacteria from the dentinal tubules, leading to rapid inclination towards the usage of biologic medication derived from natural plants. The main advantages of utilizing herbal alternatives are their cost-effectiveness, low toxicity, easy availability, increased shelf life, and decreased microbial resistance. ${ }^{10}$

Azadirachta Indica (Neem) contains immense amount of chemically diverse biologically active compounds that inhibits the vitality of the bacteria by hampering the respiratory chain. ${ }^{11}$

These active compounds include azadirachtin, nimbidin, margolone, nimbin, nimbolide, gedunin, cyclictrisulphide, and mahmoodin. They inhibit the "mitochondrial oxidative phosphorylation" thereby inhibiting the "respiratory chain". ${ }^{12}$

In India, Tulsi has been famously considered as "The Queen of the herbs" for its restorative and spiritual properties. ${ }^{13}$ Tulsi (Ocimum sanctum) contains active components such as Eugenol, ursolic acid and carvacrol, which are responsible for its antimicrobial activity. ${ }^{14}$

Pomegranate (Punica granatum) belonging to family punicaceae, is a small tree or shrub native to Asia. It contains phenolic compounds, including flavonoids (catechins, anthocyanins, and other complex flavonoids) and hydrolysable tannins (pedunculagin, punicalagin, punicalin, gallic and ellagic acid). Punica granatum peel has free radical-scavenging properties. ${ }^{15}$ Besides accounting for majority of its antioxidant activity, these compounds also exhibit antifungal, antibacterial and antiproliferative properties. ${ }^{16}$

It is essential to explore new antimicrobial agents that are productive in eradicating the tenacious bacteria in the root canal systems. Therefore, in this study, three herbal agents were chosen to test their antibacterial efficacy against E.faecalis.

\section{METHODOLOGY}

Punica granatum (Pomegranate) peel powder, Azadirachta indica (Neem) and Ocimum tenuifloram (Tulsi) leaves powder was procured commercially. The aqueous extract solutions were prepared of $80 \%$ concentration which were used for MIC determination using Broth micro dilution method.

\section{Preparation of specimens}

A total of 48 freshly extracted, intact single rooted, permanent mandibular premolars extracted due to orthodontic reasons, were collected. The teeth were decoronated at CEJ (Cementoenamel junction) using a sterile diamond disc to obtain $14 \mathrm{~mm}$ of root structure.

The patency of the apical foramen was established. Canals were then prepared with Protaper-gold files (PTG, Dentsply Sirona) up to an apical size of F3. The specimens were then kept in an ultra-sonic bath of $17 \%$ EDTA for 5 minutes followed by $3 \% \mathrm{NaOCl}$ for 5 minutes to remove inorganic and organic debris. They were then immersed in ultrasonic bath containing distilled water for removal of remaining chemical traces for 5 minutes and were then dried using a size 25 sterile paper point for one minute. Two cycles of autoclaving were done for all the specimens. Cycle one was carried out at $121^{\circ} \mathrm{C}$ and cycle two with the specimens immersed in $1 \mathrm{~mL}$ of Brain Heart Infusion (BHI) broth in individual microcentrifuge tubes.

\section{Contamination of the specimens}

Blood agar plates were used for cultivation of E. faecalis (ATCC 29212) over 24 hours following which a suspension of this culture was prepared in $5 \mathrm{ml}$ of $\mathrm{BHI}$ broth. Incubation at $37^{\circ} \mathrm{C}$ was carried out for four hours and turbidity of this suspension was adjusted to $0.5 \mathrm{McF}$ arland. Each of the prepared tooth samples was put in the sterile microcentrifuge tubes with $1 \mathrm{~mL}$ of sterile BHI Broth. Fifty microlitres of the initially prepared E. faecalis inoculum was added to each microcentrifuge tube. Purity of the culture was confirmed by subculturing $5 \mathrm{ml}$ of the broth taken from the incubated samples on blood agar plates. Contamination of the samples was conducted for a period of 7 days.

\section{Antimicrobial assessment}

After completion of 7 days, $5 \mathrm{~mL}$ of sterile saline was used to remove the incubation broth from each sample. They were then randomly distributed into 4 groups ( $\mathrm{n}=12$ teeth). 
Mittal A, et al: Comparison of Antibacterial Activity of Calcium Hydroxide, Azadirachta Indica (Neem), Ocimum Tenuiflorum (Tulsi) and Punica Granatum (Pomegranate) Gels as Intracanal Medicaments Against Enterococcus Faecalis: An In-vitro Study

Group I- Calcium hydroxide mixed with saline till a paste like consistency was obtained

Group II- 5\% Neem gel prepared using carboxy-methyl cellulose as the thickening agent

Group III- 10\% Tulsi gel prepared using carboxy-methyl cellulose as the thickening agent

Group IV- 10\% Pomegranate gel prepared using carboxy-methyl cellulose as the thickening agent

The medicaments were then introduced within the canals and secured with paraffin wax at both ends. Then incubation was carried out in aerobic environment at $37^{\circ} \mathrm{C}$. A microbial cells assessment was carried out with 4 specimens at the end of 1,3 and 5 days.

The H-file was placed to the working length, and with filing motion, the dentinal shavings were scraped from apical third to a coronal third of a canal. The obtained dentinal shavings were then placed into $1 \mathrm{~mL}$ of sterile $\mathrm{BHI}$ broth and incubated in aerobic environment at $37^{\circ} \mathrm{C}$ for 24 hours. After 24 hours, fifty $\mu \mathrm{L}$ of the dilution was plated on BHI agar plates and again incubation was carried out for 24 hours. Colonies were counted and readings recorded.

\section{STATISTICAL ANALYSIS}

The data obtained was tabulated and analysed using SPSS software version 23.0. The results in the study were subjected to One way ANOVA test and Post- hoc Tukey test.

\section{RESULTS}

All the experimental groups in the study showed antibacterial activity. Table 1 displays the antibacterial activity, at 3 selected time intervals (1, 3 and 5 days). Calcium hydroxide showed the maximum antibacterial activity followed by Pomegranate gel with no statistically significant difference between them. Similarly, there was no statistically significant difference observed between the mean CFU/ml values of the neem and tulsi gel, at different time intervals. However, pomegranate gel showed statistically significant antibacterial activity when compared to Neem and Tulsi. On the basis of above analysis, the order of microbial efficacy of different medicaments derived was-

$\mathrm{Ca}(\mathrm{OH})_{2}>$ Pomegranate $>$ Neem $>$ Tulsi.

\section{DISCUSSION}

In this study, mandibular first premolars were used rather than bovine teeth as they simulate the clinical scenario better in assessment of endodontic medicaments efficacy in disinfection of dentinal tubules. ${ }^{17}$ First and third day were chosen to evaluate the antimicrobial action as it has been previously reported that antibacterial efficacy of intra-canal medicaments reduces after 48 hours. ${ }^{18}$ An additional evaluation was done on the 5th day based on a study by Beltes et al which reported that sufficient hydroxyl ions are released by $\mathrm{Ca}(\mathrm{OH})_{2}$ over a period of 5 days. ${ }^{19}$

In this study, gel form of medicament was chosen as it renders ease of placement inside the root canal and better stay of the material within the canal walls. Also, probability of extrusion of material beyond the apex is minimized with a gel-based consistency. ${ }^{20}$ For antibacterial assessment, Colony Forming Units were counted as it has been previously reported as the gold standard method. One of its advantages is that it does not include dead bacteria or debris and only the viable bacteria are counted. ${ }^{21}$

For the antimicrobial assessment, mean $\mathrm{CFU} / \mathrm{ml}$ values obtained were subjected to statistical analysis which revealed that among the four experimental groups, $\mathrm{Ca}(\mathrm{OH})_{2}$ demonstrated the maximum antibacterial efficacy which was comparable to the pomegranate gel group. However, the mean $\mathrm{CFU} / \mathrm{ml}$ values of pomegranate and calcium hydroxide was significantly lower as compared to the neem and tulsi group. Our study demonstrated that out of the three herbal gels, only $10 \%$ pomegranate gel was efficient enough to reduce the $\mathrm{E}$ faecalis count to a level comparable to the gold standard calcium hydroxide over a period of five days. Our results were in accordance with study published by Ahmet D. Duman et al in 2009 in which P.granatum showed antibacterial efficacy against E.faecalis at $40 \mu \mathrm{g} / \mathrm{ml} .{ }^{22}$ Visveswaraiah et al in 2015 also reported inhibitory effect of P.granatum on E.faecalis at MIC of $100 \mu \mathrm{g} / \mathrm{ml} .{ }^{15}$ Another study conducted by S. Aravindraj et al in 2017 reported prominent antibacterial efficacy of P. Granatum peels against E. faecalis. ${ }^{23}$

The reason for higher minimum inhibitory concentrations in the present study might be due to the use of distilled water-based extracts and not any other solvent based, as solvents (like benzene and alcohol based) enhance the antimicrobial potential of the actual extracts and also have toxic effects on periapical tissues. ${ }^{24}$ For eg., if exposed in larger amounts \& for longer duration, benzene exposure has been shown to cause an inflammatory response, hematotoxicity and leukemia. Likewise, alcohol based extracts are said to disrupt the physical structure of cell membranes, if not used judiciously. ${ }^{25}$

Not many articles are reported in previous literature regarding antibacterial efficacy of P. granatum against E.faecalis, however, Abdollahzadeh et al and Saad Sabbar Dahham et al in 2010 reported excellent antibacterial activity of P.granatum against S.aureus. ${ }^{26-27}$ In our study, significant antibacterial activity of P.granatum peel powder can be attributed to the presence of substantial amounts of phenolic compounds, including flavonoids (anthocyanins, catechins and other complex flavonoids) and hydrolysable tannins (punicalagin, punicalin, pedunculagin, gallic and ellagic acid), gallic acid and ellagic acid, which have free radical-scavenging properties, and account for $92 \%$ of the antioxidant activity. ${ }^{28}$

$5 \%$ Neem was selected as another experimental group because of its antibacterial activity attributed to the presence of astringents and salts like calcium, chloride, sulphur and fluoride. Neem contains sterols, oils, resins, silica, flavonoids, gum and alkaloids. Calcium present in neem, acts as an abrasive agent and is responsible for tooth polishing. Analgesic property is due to the Tannins present as astringent. In the present study, though Neem gel showed antibacterial activity against E.faecalis, it did not prove to be as effective as calcium hydroxide or pomegranate gel. Many previous studies like Rosaline et al (2013), Mistry et al (2014), Mustafa M (2016), Bharadwaj et al (2017) reported significant antibacterial activity of neem against E.faecalis. ${ }^{11,29,30}$ However, none of these studies compared antibacterial activity of neem with calcium hydroxide or pomegranate. Also, another study Hugar et al in 2017 reported ineffectiveness of neem in oil form against E.faecalis. $^{31}$

$10 \%$ Tulsi gel in our study reduced the colony count of E.faecalis. This is in accordance with previous literature like Mistry et al (2014), Mukka et al (2017), Kalita C et al (2019), all of which demonstrated antibacterial activity of tulsi against E.faecalis. ${ }^{29,32}$ It contains Eugenol, ursolic acid and carvacrol as the active component which are responsible for its antimicrobial activity. However, Jain et al (2015), Bharadwaj et al (2017), Kalita et al (2019) compared the antibacterial efficacy of neem and tulsi extracts against E.faecalis and concluded that neem was more efficacious than tulsi, as observed in this study. ${ }^{33}$

Calcium hydroxide proved to be the most efficacious medicament against E.faecalis. This is in accordance with several studies Varshini et al (2019), Samiei et al (2018), Louwakul et al (2016). ${ }^{34-35}$ The antibacterial efficacy of calcium hydroxide can be attributed to the release and diffusion of hydroxyl ions $\left(\mathrm{OH}_{-}\right)$that results in a highly 
Mittal A, et al: Comparison of Antibacterial Activity of Calcium Hydroxide, Azadirachta Indica (Neem), Ocimum Tenuiflorum (Tulsi) and Punica Granatum (Pomegranate) Gels as Intracanal Medicaments Against Enterococcus Faecalis: An In-vitro Study

alkaline environment which is not favorable for the survival of microorganisms. Its fatal effects are due to various mechanisms such as A) direct action of hydroxyl ions cause damage to the cytoplasmic membrane of bacteria B) suppression of enzyme activity and cellular metabolism disruption C) Splitting DNA thereby inhibiting DNA replication. ${ }^{36}$

However, there are many studies such as DiFiore et al. (1983), Haapasalo \& Ørstavik (1987), Siqueira \& Uzeda (1996), Weiger et al. (2002), Ballal et al. (2007), Krithikadatta et al. (2007) which reported the inefficacy of $\mathrm{Ca}(\mathrm{OH})_{2}$ against E.faecalis. This may be due to dense bacterial biofilms and escape of E. faecalis from hydroxyl ions as it penetrates into the canal isthmus and irregularities. ${ }^{37}$ Also, due to the proton pump present in E.faecalis that acidifies the cytoplasm, enables it to resist the calcium hydroxide action at or below $\mathrm{pH}=11.1 .^{38}$

Sjögren et al. ${ }^{39}$ demonstrated that using calcium hydroxide powder with different vehicles such as saline, distilled water and anaesthetics help in maintaining the high $\mathrm{pH}$ for at least 7 days. Polyethylene glycol, glycerine and other viscous mediums lead to very slow release of calcium and hydroxyl ions for a longer period. In the situations, that calcium hydroxide has to be placed in canal for a long time for it to be beneficial..$^{40}$ Behnan et al in 2001 demonstrated that less viscous preparations were more efficacious in removal of E.faecalis as compared to viscous preparations upto 24 hours. Therefore, in this study saline was selected as a vehicle for $\mathrm{Ca}(\mathrm{OH})_{2}$ as the experimental time was 5 days.

This study provided evidence that over the five-day period pomegranate was successful as an intracanal medicament and this has not been previously reported in scientific literature. Therefore, there is a scope for further research with a longer observation period.

Further long-term clinical trial must be conducted to know the effectiveness of the extract solutions as intracanal medicaments. The extracts should also be tried in-vivo, to evaluate their toxicity and allergic potential.

\section{REFERENCES}

1. Kakehashi S, Stanley HR, Fitzgerald RJ. The effects of surgical exposures of dental pulps in germ-free and conventional laboratory rats. Oral Surgery, Oral Med Oral Pathol. 1965;

2. Grossman LI. Endodontic practice, ed 10. J Endod. 1982;

3. C.H. S, S.A. S, T.J. B, C.B. O. Enterococcus faecalis: Its role in root canal treatment failure and current concepts in retreatment. J Endod. 2006;

4. Siqueira JF. Aetiology of root canal treatment failure: Why welltreated teeth can fail. International Endodontic Journal. 2001.

5. Garg P, Maccune E, Malik V, Singh U, Sinha D, Tyagi S. Comparison of antimicrobial efficacy of propolis, Morinda citrifolia, Azadirachta indica, triphala, green tea polyphenols and $5.25 \%$ sodium hypochlorite against Enterococcus fecalis biofilm. Saudi Endod J. 2014;

6. Portenier I, Waltimo T, Ørstavik D, Haapasalo M. The susceptibility of starved, stationary phase, and growing cells of Enterococcus faecalis to endodontic medicaments. J Endod. 2005;

7. Tang G, Samaranayake LP, Yip HK. Molecular evaluation of residual endodontic microorganisms after instrumentation, irrigation and medication with either calcium hydroxide or Septomixine. Oral Dis. 2004;

8. Fava LRG, Saunders WP. Calcium hydroxide pastes: Classification and clinical indications. International Endodontic Journal. 1999.

9. Torabinejad M, Ung B, Kettering JD. In vitro bacterial penetration of coronally unsealed endodontically treated teeth. J Endod. 1990;

10. SHARAD K, RAJEEV K, PRAHLAD S. Role of herbs in endodontics: An update. Endodontology. 2015;
11. Rosaline H, Kandaswamy D, Gogulnath D, Rubin MI. Influence of various herbal irrigants as a final rinse on the adherence of Enterococcus faecalis by fluorescence confocal laser scanning microscope. J Conserv Dent. 2013;

12. Biswas K, Chattopadhyay I, Banerjee RK, Bandyopadhyay U. Biological activities and medicinal properties of neem (Azadirachta indica). Current Science. 2002.

13. Vishwakarma A. A Review on Antimicrobial Potential of Indian Ocimum sanctum (Tulsi). Int J Sci Res. 2017;

14. Agarwal P, Nagesh L, Murlikrishnan. Evaluation of the antimicrobial activity of various concentrations of Tulsi (Ocimum sanctum) extract against Streptococcus mutans: An in vitro study. Indian J Dent Res. 2010;

15. P.M. V, K. M, S.S. V. Antimicrobial activity of Punica granatum and Psidium guajava on Candida albicans and Enterococcus faecalis: An In-Vitro study. Res J Pharm Biol Chem Sci. 2015;

16. Foss SR, Nakamura C V., Ueda-Nakamura T, Cortez DAG, Endo EH, Dias Filho BP. Antifungal activity of pomegranate peel extract and isolated compound punicalagin against dermatophytes. Ann Clin Microbiol Antimicrob. 2014;

17. Basrani B, Tjäderhane L, Santos JM, Pascon E, Grad H, Lawrence $\mathrm{HP}$, et al. Efficacy of chlorhexidine- and calcium hydroxide-containing medicaments against Enterococcus faecalis in vitro. Oral Surg Oral Med Oral Pathol Oral Radiol Endod. 2003.

18. Neelakantan P, Sanjeev K, Subbarao C V. Duration-dependent susceptibility of endodontic pathogens to calcium hydroxide and chlorhexidene gel used as intracanal medicament: an in vitro evaluation. Oral Surgery, Oral Med Oral Pathol Oral Radiol Endodontology. 2007;

19. Beltes PG, Pissiotis E, Koulaouzidou E, Kortsaris AH. In vitro release of hydroxyl ions from six types of calcium hydroxide nonsetting pastes. J Endod. 1997;

20. Al-Sudani DA, Al Omar HA. Evaluation of sodium hypochlorite (NaOCl) gel as an endodontic irrigant. J Biomater Tissue Eng. 2011;

21. Hazan R, Que YA, Maura D, Rahme LG. A method for high throughput determination of viable bacteria cell counts in 96-well plates. BMC Microbiol. 2012;

22. Duman AD, Ozgen M, Dayisoylu KS, Erbil N, Durgac C. Antimicrobial activity of six pomegranate (Punica granatum L.) varieties and their relation to some of their pomological and phytonutrient characteristics. Molecules. 2009;

23. Aravindraj S, Preethi M, Sivapathasundharam B. Antimicrobial Effects of Punica granatum Extracts on Staphylococcus aureus, Streptococcus mutans, Lactobacillus acidophilus, Enterococcus faecalis and Candida albicans. Int J Curr Microbiol Appl Sci. 2017;

24. Zhang L, McHale CM, Rothman N, Li G, Ji Z, Vermeulen R, et al. Systems biology of human benzene exposure. Chemico-Biological Interactions. 2010

25. Goldstein DB. Effect of alcohol on cellular membranes. Ann Emerg Med. 1986:

26. Abdollahzadeh S, Mashouf R, Mortazavi H, Moghaddam M, Roozbahani N, Vahedi M. Antibacterial and antifungal activities of punica granatum peel extracts against oral pathogens. J Dent (Tehran) [Internet]. 2011;8(1):1-6. Available from: http://www.ncbi. nlm.nih.gov/pubmed/21998800\%0Ahttp://www.pubmedcentral.nih. gov/articlerender.fcgi?artid=PMC3184731

27. Soeda M, Otomo M, Ome M, Kawashima K. Studies on anti-bacterial and anti-fungal activities of Cape aloe. Nippon saikingaku zasshi Japanese J Bacteriol. 1966;21(10):609-14.

28. Lu J, Wei Y, Yuan Q. Preparative separation of punicalagin from pomegranate husk by high-speed countercurrent chromatography. $J$ Chromatogr B Anal Technol Biomed Life Sci. 2007: 
Mittal A, et al:: Comparison of Antibacterial Activity of Calcium Hydroxide, Azadirachta Indica (Neem), Ocimum Tenuiflorum (Tulsi) and Punica Granatum (Pomegranate) Gels as Intracanal Medicaments Against Enterococcus Faecalis: An In-vitro Study

29. Mistry KS, Sanghvi Z, Parmar G, Shah S. The antimicrobial activity of azadirachta indica, mimusops elengi, tinospora cardifolia, ocimum sanctum and $2 \%$ chlorhexidine gluconate on common endodontic pathogens: An in vitro study. Eur J Dent. 2014;

30. Mustafa M. Antibacterial efficacy of neem (Azadirachta indica) extract against Enterococcus faecalis: An in vitro study. J Contemp Dent Pract. 2016;

31. Hugar S, Patel PM, Nagmoti J, Uppin C, Mistry L, Dhariwal N. An in vitro Comparative Evaluation of Efficacy of Disinfecting Ability of Garlic Oil, Neem Oil, Clove Oil, and Tulsi Oil with autoclaving on Endodontic K Files tested against Enterococcus faecalis. Int J Clin Pediatr Dent. 2017;10(3):283-8

32. Mukka PK, Pola SSR, Kommineni NK, Pachalla MS, Karne AR, Labishetty K, et al. Comparative evaluation of three herbal solutions on the disinfection of guttapercha cones: An in vitro study. J Clin Diagnostic Res. 2017;

33. Bhardwaj A, Srivastava N, Rana V, Adlakha V, Asthana A. How efficacious are Neem, Tulsi, Guduchi extracts and chlorhexidine as intracanal disinfectants? A comparative ex vivo study. AYU (An Int O J Res Ayurveda). 2017;
34. Samiei M, Torab A, Hosseini O, Abbasi T, Abdollahi AA, Divband B. Antibacterial effect of two nano zinc oxide gel preparations compared to calcium hydroxide and chlorhexidine mixture. Iran Endod J. 2018;

35. Varshini R, Subha A, Prabhakar V, Mathini P, Narayanan S, Minu K. Antimicrobial efficacy of Aloe vera, lemon, Ricinus communis, and calcium hydroxide as intracanal medicament against Enterococcus faecalis: A confocal microscopic study. J Pharm Bioallied Sci. 2019;

36. Athanassiadis B, Abbott P V., Walsh LJ. The use of calcium hydroxide, antibiotics and biocides as antimicrobial medicaments in endodontics. Aust Dent J. 2007;

37. GOMES BPFA, DRUCKER DB, LILLEY JD. Association of specific bacteria with some endodontic signs and symptoms. Int Endod J. 1994

38. Evans M, Davies JK, Sundqvist G, Figdor D. Mechanisms involved in the resistance of Enterococcus faecalis to calcium hydroxide. Int Endod J. 2002;

39. SJÖGREN U, FIGDOR D, SPÅNGBERG L, SUNDOVIST G. The antimicrobial effect of calcium hydroxide as a short-term intracana dressing. Int Endod J. 1991;

40. Siqueira JF, De Uzeda M. Influence of different vehicles on the antibacterial effects of calcium hydroxide. J Endod. 1998;

\section{GRAPHICAL ABSTRACT}

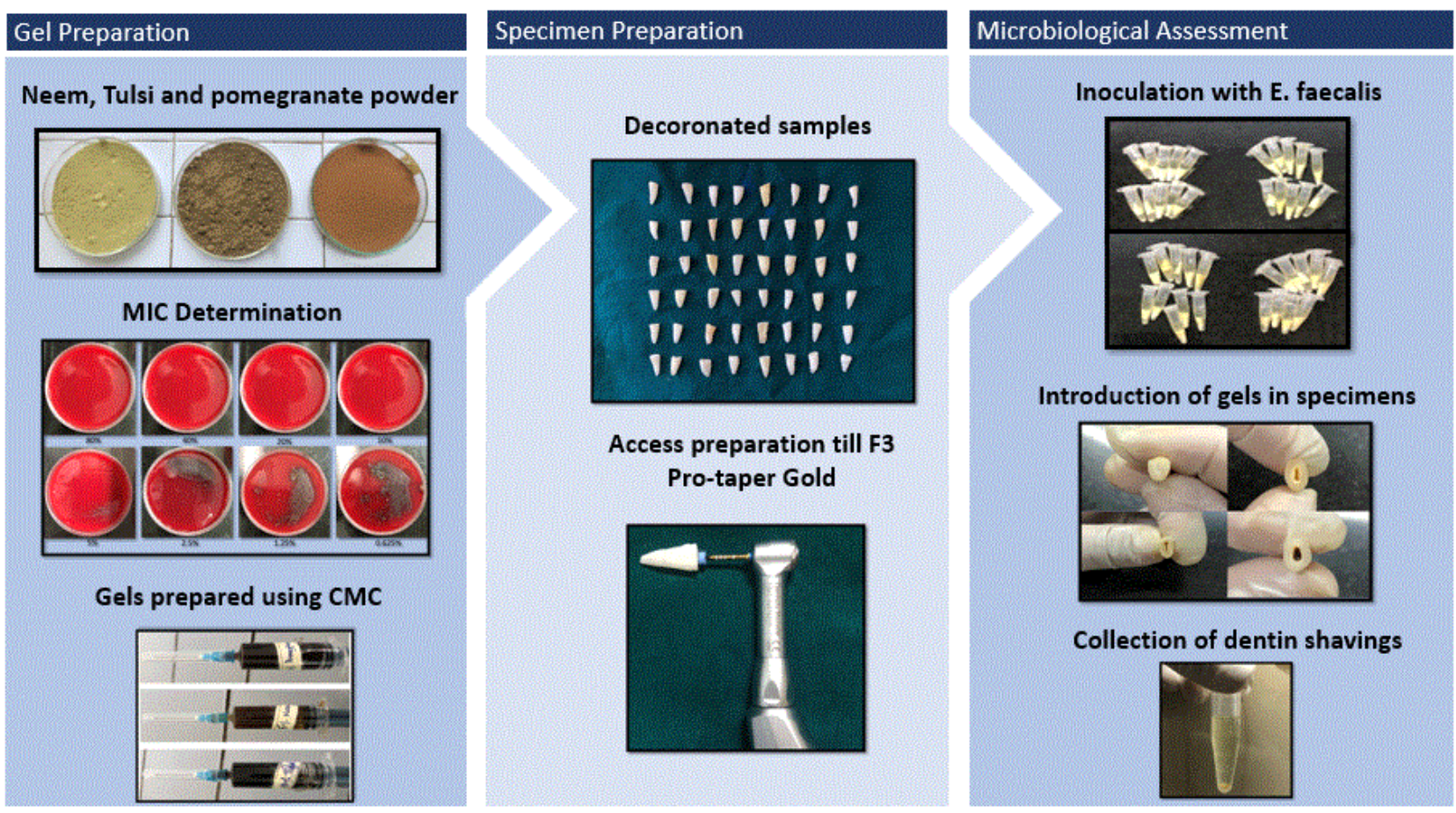




\section{ABOUT AUTHORS}

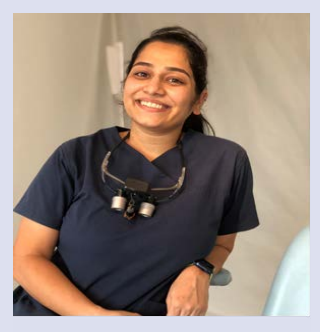

Dr Akanksha Mittal
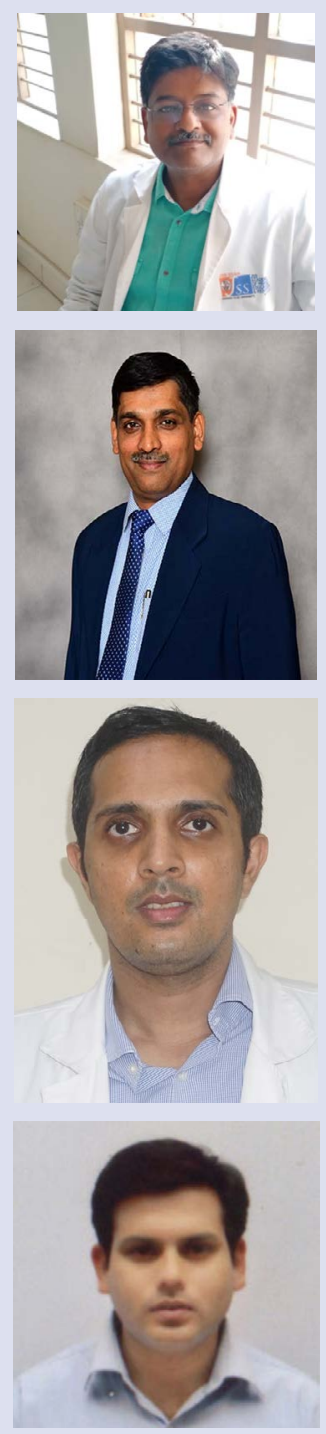

Dr Akanksha Mittal-is a final year postgraduate student in the Department of Conservative Dentistry \& Endodontics at JSS Dental College and Hospital, Mysuru. She has done her BDS from Manipal College of Dental Sciences, Manipal, Karnataka.

Dr Sunil Tejaswi- is a Reader in the Department of Conservative Dentistry \& Endodontics at JSS Dental College and Hospital, Mysuru. He has been in clinical research for the past many years and has several publications to his credit.

Dr Mruthunjaya K- is the Professor and Head of Department of Pharmacognosy at JSS Pharmacy College, Mysuru. He has a keen interest in pharmacological research and has many publications to his credit.

Dr Suneeth Shetty- is a Senior Lecturer in the Department of Conservative Dentistry \& Endodontics at JSS Dental College and Hospital, Mysuru.

Dr Ambikathanaya UK- is a Senior Lecturer in the Department of Conservative Dentistry \& Endodontics at JSS Dental College and Hospital, Mysuru.

Cite this article: Mittal A, Tejaswi S, Mruthunjaya K, Shetty S, Ambikathanaya UK. Comparison of Antibacterial Activity of Calcium Hydroxide, Azadirachta Indica (Neem), Ocimum Tenuiflorum (Tulsi) and Punica Granatum (Pomegranate) Gels as Intracanal Medicaments Against Enterococcus Faecalis: An In-vitro Study. Pharmacogn J. 2021;13(4): 988-994. 